Letter To The Edifior

Submitted: 16 Oct 2016 Accepted: 27 Nov 2016 Online: 24 Feb 2017

\section{Examination of Obstructive Sleep Apnea at Regular Intervals: An Essential Requirement for Drivers in Malaysia}

\author{
Ramasamy Chidambaram
}

Department of Prosthodontics, Faculty of Dentistry, AIMST University, Jalan Bedong-Semeling, o810o Bedong, Kedah Darul Aman, Malaysia

To cite this article: Chidambaram R. Examination of obstructive sleep apnea at regular intervals: an essential requirement for drivers in Malaysia. Malays $J$ Med Sci. 2017;24(1):121-122. https://doi.org/10.21315/ mjms2017.24.1.14

To link to this article: https://doi.org/10.21315/mjms2017.24.1.14

Sir,

Excessive daytime sleepiness (EDS) is a multi-factorial disorder that is not limited only to narcolepsy, insomnia, psychiatric medications and obstructive sleep apnea (OSA) (1). Last one has been reported as the most common cause of dramatic rise in motor vehicle crashes (MVC) in Malaysia (2). It's miserable that MVC is the second leading cause of death, foremost being the coronary heart disease (3). Further, it's sad to note that predominantly, most of such accidents occur due to human error (3). Poor quality of sleep compels the drivers to doze off, particularly, during monotonous circumstances, such as, driving, ultimately causing fatal accidents. Despite the display of prominent symptoms, like, loud noise of snoring and disturbed breathing, the sufferers tend to avoid the underlying disorder by attributing those to their nature of work (driving).

An undiagnosed case of OSA could lead to serious consequences, such as hypertension, stroke and even death. This is evident by the fact that truck drivers who neglect the symptoms of OSA are at higher risk of meeting accidents (4). Due to such physical and mental trauma, the main question remains unanswered-how to diagnose early stages of OSA in drivers? Considering the well-being of the sufferers, concerned organisations, like the Ministry of Health (MOH), Malaysia, Road Transport of Malaysia and Malaysia Institute of Road Safety Research (MIROS), have taken important preventive and supportive measures. Collaborative efforts of the stated agencies led to successful inclusion of OSA (2011) as one of the parameters to be tested during medical examination of drivers (2).

Despite the sincere efforts, recent studies in Malaysia have demonstrated alarming figures, wherein $14.6 \%$ of commercial drivers had severe OSA among 130 people. Another report showed that majority of the accidents occurs due to fatigue among express bus drivers (5). Current media reports also emphasise a critical survey on the progression of OSA and also demand ban on the driving by those suffering from severe OSA (6). Is there any possibility that inadequacies in law allowed the tremendous increase in OSA cases? Honestly, it is mandatory for the professional drivers to undergo routine medical fitness test, prior to issue of their driving license. However, due to non-practice of constant monitoring in the proposed system, the drivers tend to skip the medical check-ups at the time of renewal of their license. There is high probability that the individual's medical condition could deteriorate at any occasion during a period of one year. Henceforth, it would be reasonable to assess the candidate's physical health at least every six months of issue of the license. Secondly, the evaluation of OSA in drivers is sometimes based on questionnaires, which fail to identify severity of a disorder. Thus, objective assessments, e.g., polysomnography, which is routinely used in sleep clinics/researches can help in differentiation of high-risk subjects and must be employed for OSA examination. It's in good belief that sincere and efficient authorised agencies would implement necessary actions and re-consider examination of drivers at regular intervals, so as to ensure safety of our people and economy. 


\section{Correspondence}

Dr Ramasamy Chidambaram

MDS (Sri Ramachandra University, Tamilnadu, Chennai-116)

Department of Prosthodontics,

Faculty of Dentistry, AIMST University,

Jalan Bedong-Semeling,

o810o Bedong,

Kedah, Malaysia.

Tel: 0164724370

E-mail: dr.ramasamyc@gmail.com

\section{References}

1. Wahida AB, Ilhamah O, Suffian AM, Aimi MF, Norlen M, Wong SV. Obstructive sleep apnea among commercial vehicle drivers in Malaysia: issues and initiatives. Health. 2013;5(8):80-86. https://dx.doi.org/10.4236/health.2013.58A2012

2. Ramasamy C, Parusuraman S. Let's not ignore when the patient snores in clinic: an alarming call for oral health care professionals. $J$ Young Pharm. 2017;9(1):1-2.
3. Nik Hisamuddin NA Rahman, Kamarul A Baharuddin, Syarifah Mastura S Mohamad. Burden of motorcycle-related injury in Malaysia. Int J Emerg Med. 2015;8:(17). https://dx.doi. org/10.1186/s12245-015-0065-4

4. Nik Nor Ronaidi NM, Norsa'adah B, Norlen M, Mohd Nazri S. Risk factors for near miss incident among long distance bus drivers in Malaysia. Iranian J Publ Health. 2014;43(Suppl 3):117124.

5. Mohamed N, Mohd-Yusoff MF, Othman I, Zulkipli Z-H, Osman MR, Wong SV. Fatiguerelated crashes involving express buses in Malaysia: will the proposed policy of banning the early-hour operation reduce fatigue-related crashes and benefit overall road safety? Accid Anal Prev. 2012;45(Suppl):45-49. https:// dx.doi.org/10.1016/j.aap.2011.09.025

6. The Star Malaysia. Address the existing flaws in road regulations [Internet]. Kuala Lumpur, Malaysia [updated 2016 Oct 10]. Available from: https://www.pressreader.com/malaysia/the-star malaysia/20161010/282097751215605 